\title{
Why do I need to know this? Optics/ photonics problem-based learning in the math classroom
}

\section{Matthew Donnelly, Judith Donnelly, Stephanie Donnelly}

Matthew J. Donnelly, Judith F. Donnelly, Stephanie Donnelly, "Why do I need to know this? Optics/photonics problem-based learning in the math classroom," Proc. SPIE 10452, 14th Conference on Education and Training in Optics and Photonics: ETOP 2017, 1045209 (16 August 2017); doi: $10.1117 / 12.2263661$

SPIE Event: 14th Conference on Education and Training in Optics and Photonics, ETOP 2017, 2017, Hangzhou, China 


\title{
Why do I need to know this? Optics/Photonics problem-based learning in the math classroom \\ Matthew J. Donnelly ${ }^{\mathrm{a}}$,Judith F Donnelly* ${ }^{\mathrm{b}}$, Stephanie Donnelly ${ }^{\mathrm{c}}$ \\ ${ }^{a}$ St. Bernard School, Montville, CT USA 06382 \\ ${ }^{\mathrm{b}}$ Three Rivers Community College (retired), Norwich, CT 06360 \\ ${ }^{\mathrm{c}}$ Emerson College, Boston, MA
}

\begin{abstract}
A common complaint of engineering managers is that new employees at all levels, technician through engineer, tend to have rote calculation ability but are unable to think critically and use structured problem solving techniques to apply mathematical concepts. Further, they often have poor written and oral communication skills and difficulty working in teams. Ironically, a common question of high school mathematics students is "Why do I need to know this?" In this paper we describe a project using optics/photonics and Problem Based Learning (PBL) to address these issues in a high school calculus classroom.
\end{abstract}

Keywords: optics education, active learning, secondary mathematics, critical thinking, problem-based learning, math enrichment, STEM

\section{INTRODUCTION}

Over the course of an academic year, a class of eighteen high school honors calculus students engaged in three optics/photonics related Problem Based Learning (PBL) Challenges. Challenges were chosen to illustrate topics relevant to calculus: Trigonometry (International Lighting Display Association, laser safety), area under curves (California State Polytechnic University at Pomona, light measurement) and rates of change (IPG Photonics, laser cleaning of aluminum). In addition to technical resources to assist problem solving, the Challenges provide students with a problem-solving tool known as the "Whiteboards" to help them practice structured problem solving. The Whiteboards require that teams of students discuss and record the details of each step of the problem-solving process as they work on the Challenge.

Pre- and post-testing was conducted using the Motivated Strategies for Learning Questionnaire (MSLQ) to assess any changes in attitudes toward learning (motivation) and learning strategies. A focus group of students was also interviewed after the project by a neutral third party to determine their attitudes toward problem solving, learning mathematics and working on the optics/photonics related Challenges.

\section{MATH AND OPTICS}

St. Bernard School is a Catholic co-educational school in Uncasville, Connecticut that is co-sponsored by the Diocese of Norwich and the Xavierian Brothers and serves students in grades 6-12. As of the 2016-2017 school year St. Bernard has the most advanced mathematics program in Eastern Connecticut, offering courses including Multivariable Calculus, Differential Equations, and Mathematics Research. For the past several years St. Bernard School has had a thriving partnership with various organizations in China, allowing students from several locations (primarily near Beijing and Shanghai) to attend school in Connecticut. Approximately $15 \%$ of the student body is international.

Students in the Honors Calculus course come with a wide range of mathematical ability, but all have completed mathematics up through pre-calculus and some amount of physics and chemistry. In general, these students have been taught strictly using traditional lecture methods, perhaps with very occasional group work on projects. None had any previous exposure to PBL methods.

Previously, the authors collaborated on a project to introduce optics/photonics into a high school pre-calculus class in the form of hands-on experiments chosen to illustrate topics from the math course. Pre-calculus is a course many students find difficult because of the large number of seemingly unrelated topics. We hoped to show some of the interesting optics/photonics applications of topics such as trigonometry, logarithms, exponents and conic sections. Results of 
pre/post surveys and written student comments indicated that students' appreciation for applications of mathematics was increased by the project. ${ }^{1}$ While the students enjoyed their exposure to optics/photonics, they had engaged in activities with a predetermined outcome. The present project continues the exploration of applications of mathematics in optics/photonics, but with the added benefit of an introduction to structured problem solving.

\section{PROBLEM-BASED LEARNING AND THE PBL PROJECTS}

\subsection{What is Problem-Based Learning?}

Problem-Based Learning (PBL) was developed for medical education in the late 1960s by Howard Barrows and colleagues at McMaster University in Canada. Since that time it has been widely adopted in other fields including law, business, engineering and even police training. Research shows that PBL improves students' learning and retention, motivation, critical thinking and problem-solving skills, and their ability to skillfully apply knowledge in new situations. $^{2-4}$ Similar to Project-Based Learning, the focus in Problem-Based Learning is on solving open-ended authentic problems. Unlike Project-Based Learning, Problem-Based Learning does not need to result in the creation of a product. This can be an advantage because it allows challenging students with problems that might otherwise be too expensive, time consuming or unsafe in a school situation. ${ }^{5}$

PBL can be implemented in many ways, but there are elements common to all:

- Problems are presented before any formal instruction; the problem itself drives the learning of new information.

- Students work collaboratively in teams to frame the problem, research necessary information and propose and present solutions.

- The instructor acts as a facilitator who provides instruction to teams as needed ("mini lectures") and guides students as necessary to keep them on track.

In 2006, responding to input from the optics/photonics industry, the New England Board of Higher Education (NEBHE, Boston, MA) applied for a 3-year grant from the U. S. National Science Foundation's Advanced Technological Education (NSF/ATE) program to fund a project called PHOTON PBL. Previously, NEBHE had completed three NSF/ATE grant funded projects (1995-2006), collectively known as the PHOTON Projects, that developed curriculum for teaching optics/photonics primarily to engineering technicians who are graduates of 2-year postsecondary programs. The PHOTON Projects created "regional alliances" of secondary and post-secondary faculty and nearby photonics industries to facilitate a "pipeline" from high school through 2- and 4-year college to the workplace. The projects eventually included faculty from 26 U.S. states and Romania, many of whom are still in contact via an email listserv. The PHOTON Projects developed materials ranging from a high quality laboratory kit with 26 experiments and a collection of videos of the principle investigators performing the experiments to an introductory algebra/trig based textbook suitable for a one-year course introduction to optics and photonics. Much of this curriculum material is still available on the PHOTON Projects web site. ${ }^{6,7}$

\subsection{The PBL Projects}

By 2005, industry complaints were less about an insufficient number of technicians but rather a lack of workplace readiness in new employees. Although students had learned the facts and could solve typical "back of the chapter" problems, they were unable to use critical thinking skills to solve new problems on the job. Employers also remarked about recent graduates' inability to work productively in teams and to communicate effectively both orally and in writing. A new classroom model beyond the old lecture/homework/test style of instruction would be needed to develop technicians to be teamwork-oriented problem solvers able to adapt to the changing needs of business and industry. PHOTON PBL and the two additional NSF/ATE PBL projects that followed were designed to give students the chance to practice real workplace problem solving skills while still in school.

Over the course of the three PBL Projects (2006-2016), the NEBHE team developed twenty-one "Challenges", or case studies, with input from industry, university research groups and nonprofit agencies from across the U.S. Each project deals with a different area of STEM although there is some overlap: optics/photonics (PHOTON PBL), sustainable technologies (STEM PBL) and advanced manufacturing (AM-PBL). Each partner allowed the NEBHE team free access to their facility to document a problem that they had solved, for example, designing an ergonomic lighting system for a submarine workstation or developing an unattended 100-hour burn-in test procedure for a high power laser. Solved problems were chosen because teachers new to PBL sometimes needed a baseline for evaluating student solutions. Later 
we realized that this also allows students to compare their own solutions to the company's solution. They can then explore whether or not there were issues of time, money, facilities or ethics that the company had to consider that students might have missed.

The PBL Projects also continued the PHOTON Projects practice of forming geographic alliances of educators and local industry and they provided professional development to hundreds of teachers across the U.S. Understanding that teachers may be reluctant to attempt a new teaching method so different from what they are accustomed to, the NEBHE PBL team developed a suite of teacher resources including general implementation suggestions, assessment techniques, videos of PBL in the classroom, and Challenge-specific resources. These are all available on the web at no cost (although some items are password protected to prevent students from stumbling onto the company's solution). ${ }^{8}$

\subsection{Practical PBL in the Classroom}

Students may be reluctant to fully engage in PBL especially if they have spent their previous years in traditional educational settings. ${ }^{9}$ They may be so accustomed to having the teacher being the sole source of knowledge (the "sage on a stage") that they are unable to engage in self-directed learning. If their only experience is with back-of-chapter problems they may be overwhelmed by the messiness of real-life problems. Further, many students have had bad experiences working in teams in an academic setting where one or more partners contributes little to the project.

To assist students in their problem solving efforts, the Whiteboards tool is embedded in each PBL Challenge. (See Figure 1.) Students use this tool to engage in a systematic process that starts with Problem Analysis, clearly stating the problem, reflecting on the requirements of a successful solution, and listing what is known about the problem, what assumptions must be made and what needs to be learned. In the second Whiteboard, students divide up the task of learning the knowledge necessary to solve the problem; this constitutes the Independent Research or self-directed learning phase. The team then reconvenes to Brainstorm possible solutions, choosing the most promising for Solution Testing against the original list of solution requirements. The process is recursive; if the solution does not meet all criteria listed on the first page, students must return to the problem analysis phase to reexamine their original ideas. Students are instructed to use the Whiteboards both to plan and to record their problem solving efforts.
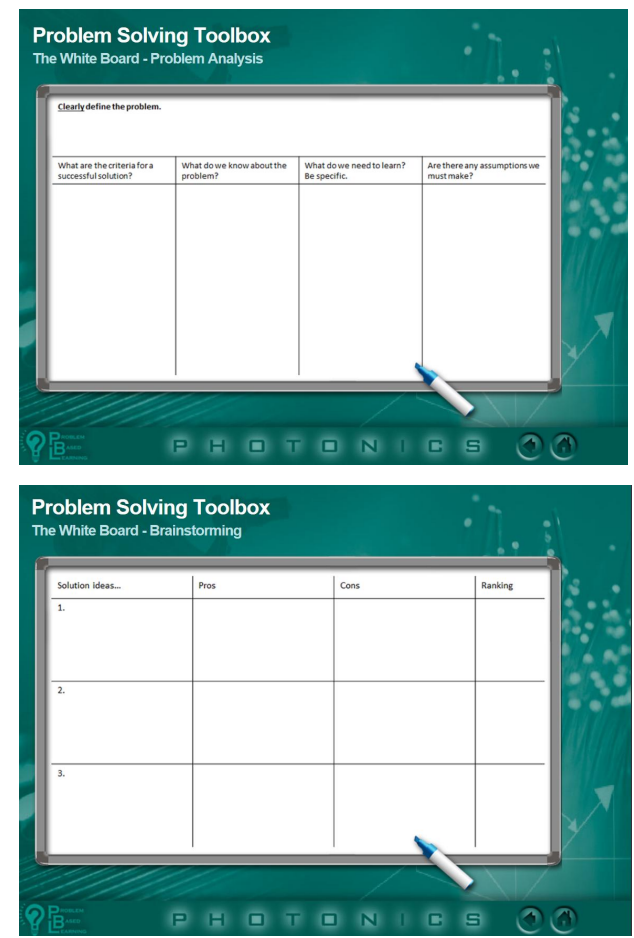
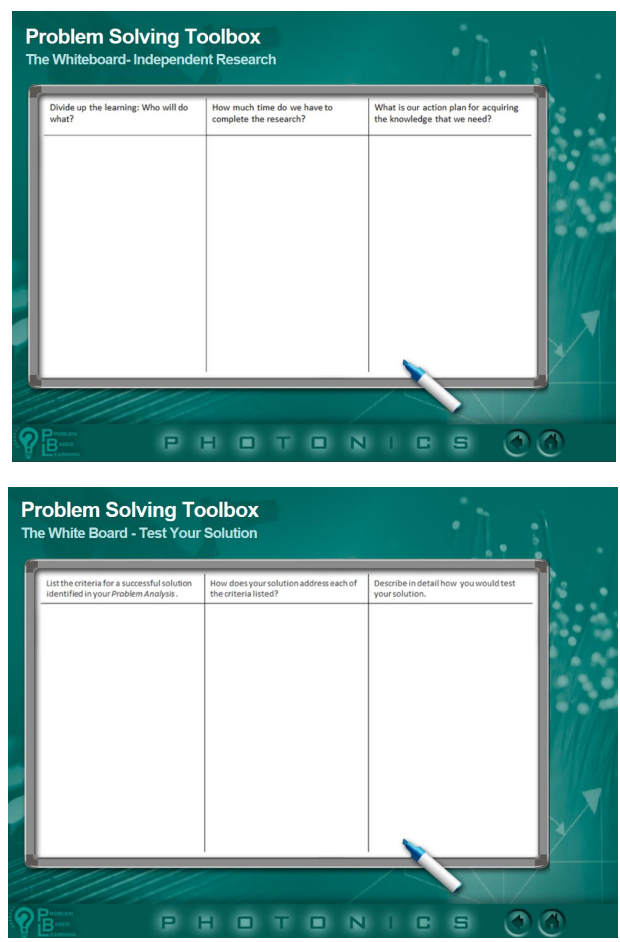

Figure 1. The Whiteboards are used to guide students in the process of structured problem solving 
The PBL Challenges are structured to make the problem as realistic as possible to students. Each has five components consisting of a short video and resources specific to that component:

- Introduction - A brief description of the science or technology behind the Challenge sets the context for the problem to be solved. Where does this topic fit in the universe of science and technology?

- Organization Overview - This short introduction to the company, university or organization that solved the problem is to remind students that the problem is from the "real world" and was solved by technicians, engineers and scientists as part of their daily work.

- Problem Statement - In this dramatization, students learn how the organization learned about the problem, for example, from a production issue or a customer request.

- Brainstorming Discussion (password protected) - The organization's team is depicted brainstorming ideas to help advance progress toward a solution.

- Organization's Solution (password protected) - Once students have presented their own solutions, this video shows how the organization solved the problem, allowing students to compare and contrast their own solutions.

Although the five videos are always presented in the same order, the time between them is at the discretion of the instructor. Novice problem solvers can be guided through the process, working through the Whiteboards with teacher assistance in just an hour or two. As students become more skilled, the instructor provides less and less assistance, for example by allowing students to work independently for a day or two before revealing the hints contained in the Brainstorming Discussion. The Challenges can also provide a weeks-long assignment for experienced problem solvers by showing the Problem and then having teams work independently until formal solutions are presented. The implementation continuum for PBL is illustrated in Figure 2.

\section{MORE INSTRUCTOR GUIDANCE}

\section{LESS INSTRUCTOR GUIDANCE}

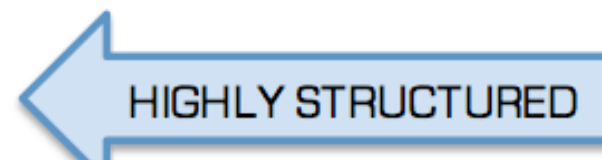

LESS STUDENT AUTONOMY

MORE STUDENT AUTONOMY

Figure 2. The PBL Implementation Continuum

Finally, the issue of assessment is addressed in the PBL Challenges by providing instructors with a framework for a four-pronged approach to evaluating and assessing student work. Tools are embedded in each Challenge to assess content knowledge (quizzes and homework), conceptual knowledge (concept mapping), problem solving skills (final Challenge report) and teamwork (peer assessment). Our interest in this project was mostly problem solving and teamwork, so students were required to submit a final Challenge report that summarizes the problem solving process and a teamwork assessment to rate themselves and their teammates on five measures of cooperation:

1. Completed specific tasks on time

2. Did his/her fair share of the work

3. Produced work of acceptable quality

4. Actively contributed to the team effort during class

5. Actively contributed to the team effort outside of class

. The Whiteboards were also collected to ensure students were not skipping steps as they progressed to a solution.

\section{CALCULUS, OPTICS AND PBL}

\subsection{Starting out: Trigonometry and laser safety}

To introduce students to the method of structured problem solving, we presented the Laser Safety Challenge ("Blinded by the Light") at the end of September 2016. Developed with the assistance of the International Laser Display Association, the Challenge asks students to assist a lawyer defending a client accused of causing permanent eye damage 
to a pilot whose plane he targeted with a laser pointer. Students needed to determine what level of exposure might cause eye damage and then calculate the pilot's exposure at a given target distance. Assumptions students needed to make included plane speed, atmospheric conditions, and effects of windscreen glass. As students worked through the Whiteboards they incorporated new knowledge of laser terms such as divergence and maximum permissible exposure (MPE) and their best guesses at the assumptions to arrive at a solution. Red laser pointers were provided to teams that wanted to explore laser divergence in the long corridor outside the classroom, providing a real life example of similar triangles and trigonometry.

The Challenge was presented over three days with the Introduction, Organization Overview and Problem Statement presented on day 1, the Brainstorming Discussion at the start of day 2 and student solutions presented on the day 3. Students were assured that the goal of the activity was to teach the process of problem solving, defined as "knowing what to do when you don't know what to do." Unlike more open-ended problems, the Laser Safety Challenge has a defined solution, making it a good first Challenge for new problem-solvers who are getting used to problems with many variables and unknowns. All teams eventually produced and shared calculations to show that the pilot could not have been permanently injured.
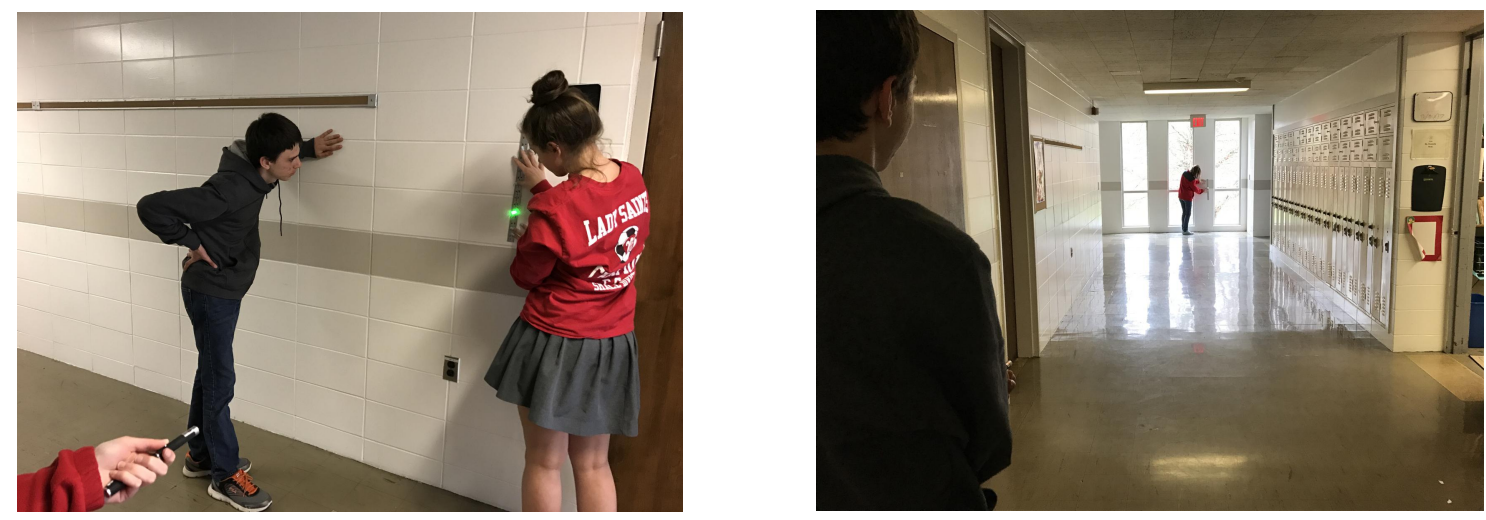

Figure 3. Students explore laser divergence with a green laser pointer as part of the Laser Safety Challenge

Students were assessed primarily on their collective thought processes as shown by the Whiteboards. Since the Challenge had a defined solution and each group discovered it in some manner, the technical details were less elucidating than were the more qualitative responses. Since they had little or no prior exposure to laser technology, many students reported that they enjoyed being able to apply concepts of trigonometry to a discipline that they found new and interesting.

\subsection{Area under a curve - the light bulb Challenge}

While still not a totally open-ended problem, the California State Polytechnic University at Pomona Challenge ("Watts My Light") presented additional computational challenges related to the calculus course. The Challenge asks students to compare the output of an incandescent bulb and to that of a compact fluorescent to see if they are equivalent. The problem is presented in the context of an informal discussion of college professors from the Cal Poly Pomona Lighting Center about a question from a journalist. The Challenge was presented over two consecutive days in November 2016, with the solutions presented one week later.

After viewing the Introduction and Organization Overview, students were shown the Problem Statement video and given time to work on the analysis Whiteboard. When used with a group of optics students, expectations are that students will learn about luminous measurements and then devise a means of actually testing the bulbs. Since these were calculus students, we were not so much interested in their delving into light measurement apparatus but rather that they see a practical use for determining the area under a curve. At the end of the first class period, students were shown the Brainstorming Discussion video (which hints at the difference between radiant and luminous units) and provided with graphs of radiant output (watts) versus wavelength for each of the bulbs. For homework we asked them to consider how this information might be used to help solve the problem. 
The following day, student teams continued to discuss and research the "missing pieces" needed to solve the problem. The instructors engaged with each team to ensure they were on the right track. By the end of the class, most teams concluded they needed to convert the given data to lumens, that is, to scale the curves before finding the area underneath using the luminosity function. We provided the luminous efficiency data in both graphical and tabular form. We also reminded students about the meaning of area under a curve and various methods of determining the area. Students then were given a week to determine from the data if the two bulbs had equivalent luminous output.
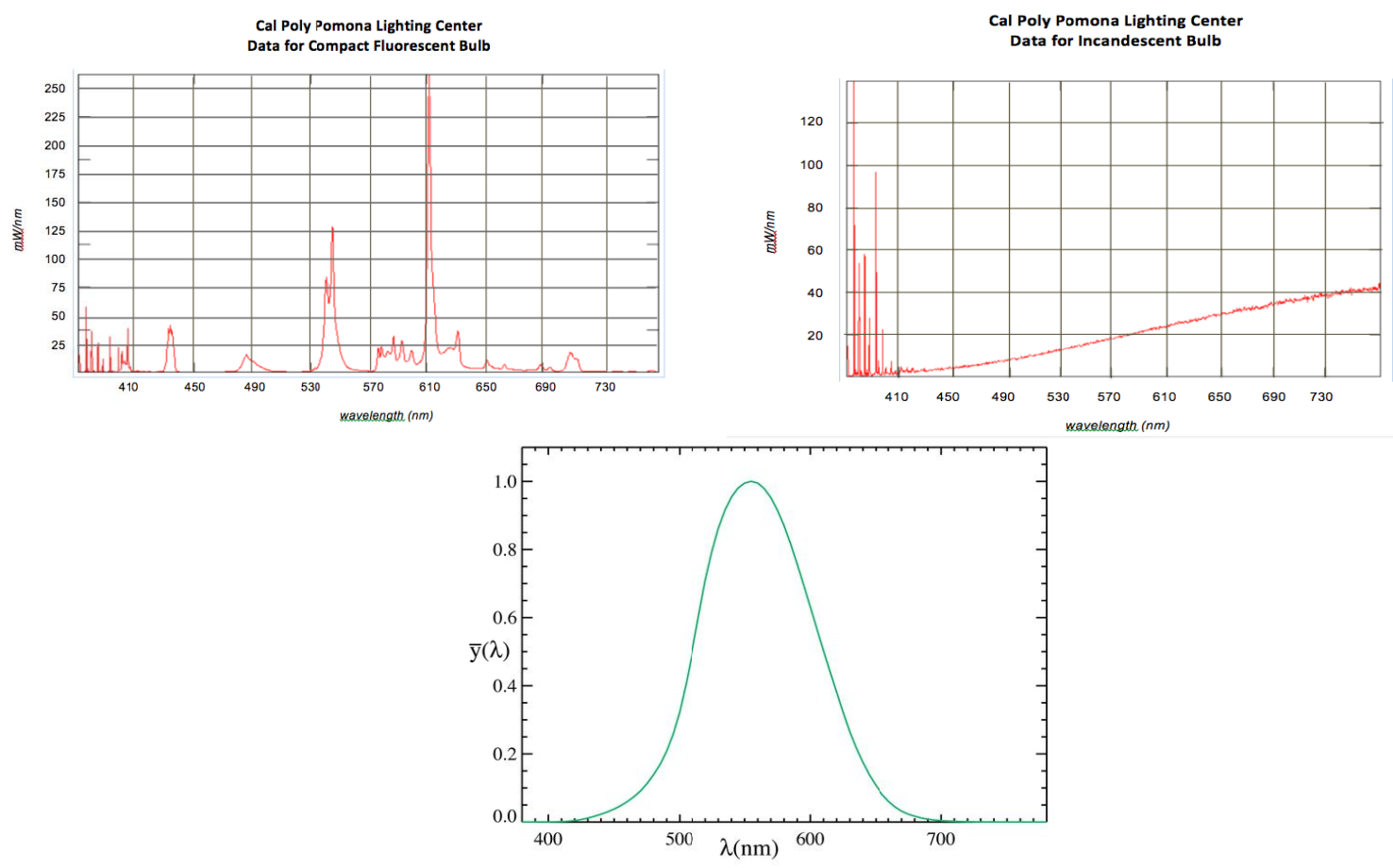

Figure 4. Data provided to students for (top, left) compact fluorescent and (top, right) incandescent bulbs. The total luminous output is the area under each curve, first multiplied by the luminous efficiency curve (bottom). (Sources: Lamp data from Cal Poly Pomona Lighting Laboratory; luminosity function from WikiPedia, public domain).

The calculations proved to be quite challenging for most students, although a few realized they could create an Excel spreadsheet to simplify the process. Scaling by hand was not too difficult for the smooth incandescent curve but rather a challenge for the fluorescent. About half the teams were able to complete the computations correctly. After students discussed their results, they were shown a student-built integrating sphere (loaned from Springfield Technical Community College in MA) and watched as a few light sources were tested with a USB spectrometer.

Again, the students were assessed primarily on their Whiteboard responses, although this time the quantitative data provided some insight as well. While each group reported that they found it easier to work as a group (especially in the area of assigning tasks and finalizing a report), their reports showed that they were missing some basic skills in geometry and especially in understanding unit conversions.

\subsection{Final test of problem solving process - Laser cleaning of aluminum}

Although we planned to complete all three Challenges during the fall semester, scheduling difficulties delayed the third activity until February 2017. The final problem was open ended and far more complex than the previous two and so we provided four class periods plus an intervening weekend to allow students ample time for research and discussion. In addition, the topic, laser cleaning of aluminum prior to welding, was completely unknown to the students. The final Challenge was designed to be a test of how well students could use the problem-solving process on a difficult problem.

The Challenge was developed with the assistance of IPG Photonics (Oxford, MA) and requires students to choose a laser, high-speed scanner and delivery optics to meet a specified cleaning rate and to develop a process to monitor the cleanliness of the aluminum. Again, we showed the Introduction, Organization Overview and Problem Statement videos 
on the first day. To simplify the problem for math students with no knowledge of laser or optical systems, we provided the laser and scanner models and a choice of two square core fiber sizes and three optical systems. (See Figure 5.) Students still needed to figure out how to move the beam across the target at the required speed while delivering the required fluence.

At the start of the second class period we showed students the company's Brainstorming Discussion and then spent the remainder of the class observing teams and providing information as needed. We continued to remind students to fill out the whiteboards and to not skip steps; the process would guide them in learning what they needed to know. While some teams made good progress toward a solution, we noted that others were bogged down in what should have been simple unit conversion calculations. We continued to work with the teams for a third class period before showing IPG's solution on the fourth day. We also introduced a model of concept mapping as a useful tool for linking different parts of a complex problem.

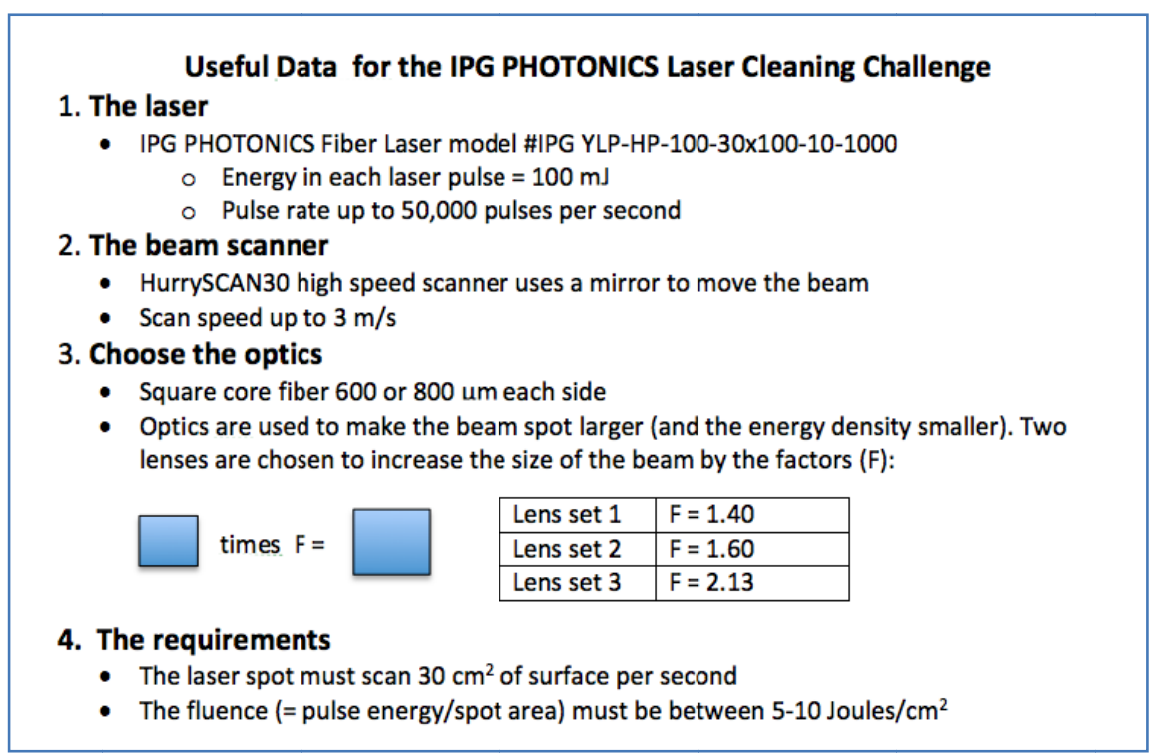

Figure 5. Data provided to students for IPG Photonics laser cleaning Challenge.

Most groups showed clear improvement in understanding and implementing positive teamwork strategies, although again many struggled with calculations and unit conversions. Said one student, "We came up with many theories and possibilities. Our group worked as a team by sticking with someone's theory until we could tell if it was right or wrong. We worked well as a team, we just weren't able to execute and achieve the goal." In general, students stated that they felt the project would have been more effective if they had more background information as the lack of it made it difficult to determine what the criteria should be for a successful outcome. We reminded them the purpose of the exercise was to see how far they could go toward solving a problem they knew nothing about, just using the tools provided. We felt some teams made impressive progress.

\section{RESULTS}

We encountered several unexpected problems introducing PBL to high school calculus students. Students in this class had almost no exposure to unstructured, open-ended problems and even given a tool (the Whiteboards), attempting the process was at first overwhelming. Students also had very little experience working in effective teams, and the short class periods (42 minutes) made it difficult to accomplish much during the time the instructor was available to facilitate. Surprisingly, despite the fact that all students had taken chemistry and about $1 / 3$ of the class was studying physics, many lacked basic science and computational skills (such as unit conversions) that are a necessary foundation for solving more complex problems. Some teams became bogged down in the minutia of computations rather than taking a broad view of the problems. 
In an attempt to obtain quantitative data on changes in students' motivation and problem solving processes, we administered the Motivated Strategies for Learning Questionnaire (MSLQ) before presenting the first Challenge (presurvey, in September, 2016) and after the last Challenge (post-survey, in March, 2017). This is a widely used and validated instrument for assessing college students' motivation and strategies for learning. Qualitative data was obtained through discussions with a focus group of five students, held approximately one month after the final Challenge activity. Students responded to four questions to determine their attitudes toward the specific activities and whether they felt their problem solving skills had been strengthened.

We saw no significant change in student motivation between pre and post MSLQ surveys except for a large positive increase in response $(\mathrm{p}<0.05)$ to the statement "I'm certain I can master the skills being taught in my classes." This correlated well with focus group students' comments on increased confidence in problem solving. Large, but not significance level increases were seen in statements indicating that students expected to do well in the course and it was their own fault if they didn't. Students were also more likely to say in the post-survey that they found the material of the course interesting. Curiously, there was also a significant decrease in the response to "It is important for me to learn the course material in my courses." Perhaps we were too insistent that learning how to be lifelong learners was more important than learning subject matter that might not be relevant in decades to come.

Although MSLQ pre/post surveys in a previous study ${ }^{10}$ showed gains in intrinsic and extrinsic motivation, self efficacy and critical thinking, the students in that case were enrolled in community college optics/photonics programs and the three Challenges were completed in a 3 month period with at least one full week allotted to each problem. The college students were older, between 25 and 35 years old, and although they were also new to PBL most had work experience that required at least some form of teamwork. It is not surprising we would see fewer attitude changes with younger, less experienced high school math students spending less time on PBL over a longer period of time.

Students in the focus group generally agreed that completing the Challenges increased their confidence in problemsolving skills by giving them specific tools for approaching open-ended problems. Most enjoyed the team approach although it was evident that additional team skills development would be beneficial. Students gained an appreciation for the tools of structured problem solving (concept mapping and the Whiteboards) and several comments indicated that the optics/photonics applications were interesting as well. Focus group comments included:

What did you like most about completing the Challenge?

- I like how we got to break the problem down and all research different things.

- I like that we each worked as a group, but we also got to each research our own things.

- It was an interesting application of some of the basic mathematics in the real world.

- I like getting to learn about the lasers and how they work. The fiber optics was cool.

What did you like least about completing the challenge?

- Working with a group can be hard if your group members don't do the work.

Has your participation in this project increased your confidence in your problem solving skills? If yes, how? If no, why?

- I liked how we structurally figured out how to do it.

- Increased because now we have a concept map that can be used for not only math but also any problem.

- I liked working in groups because it helped with leadership skills

If someone presented you with a completely open-ended problem how would you go about solving it?

- I would first figure out what the problem entails, figure out how to solved the problem by looking at the possibilities, then do research into how to solve the problem.

- I would use the method that the Whiteboards presented by figuring out what we already know and what we need to know.

\section{CONCLUSION}

Open-ended PBL Challenges involving problems in optics/photonics can be an effective way to introduce structured problem solving in the high school mathematics classroom. Incorporating elements of PBL in earlier grades, including teamwork skills, the Whiteboard tool and concept mapping, would give students more time to adapt to the method and 
strengthen their critical thinking skills as they progress to graduation. We suggest that similar studies could be done on a wider range of students, both in terms age and topic of study, to increase the use of PBL tools and improve accessibility to a variety of topics for student with multiple intelligences. Adding a content knowledge assessment prior to selecting the challenge would allow facilitators to choose problems that challenge their students appropriately and to know what areas will need to be addressed prior to or during the PBL activity.

\section{ACKNOWLEDGEMENTS}

The PHOTON and PBL projects of the New England Board of Higher Education were funded by grants from the Advanced Technological Education program of the National Science Foundation (NSF/ATE).

\section{REFERENCES}

[1] Donnelly J. and Donnelly M., "Illuminating Math with Optics", Proc. SPIE 9188, Optics Education and Outreach III, 918808 (September 15, 2014)

[2] Barrow, H.S., “A Taxonomy of Problem Based Learning Methods,” Medical Education, 20, 481-486, (1986).

[3] J.J. Kellar, W. Hovey, M. Langerman, S. Howard. L. Stetler, H. Heilhecker, L. Arneson-Meyer and S. Kellogg, "A Problem Based Learning Approach for Freshmen Engineering," Conference Proceedings Session F2G, Frontiers in Education 2000, Kansas City, MO, October (2000).

[4] Perrenet, J.C., Bouhuijs, P.A.J., \& Smits, J.G.M.M, "The Suitability of Problem-based Learning for Engineering Education: Theory And Practice," Teaching in Higher Education, 5, 3, 345-358, (2000).

[5] Larner, J. "Project-based learning vs. problem-based learning vs. X-BL, https://www.edutopia.org/blog/pbl-vs-pblvs-xbl-john-larmer (2015)

[6] The PHOTON Projects, New England Board of Higher Education, http://www.nebhe.org/photon-projects-history/

[7] Donnelly, J. and Massa, N., Light-Introduction to Optics and Photonics, New England Board of Higher Education, Boston, MA, (2007).

[8] The PBL Projects, New England Board of Higher Education, http://www.pblprojects.org

[9] Donnelly, R. \& Fitzmaurice, M., 2005, 'Collaborative project-based learning and problem-based in Higher Education: A consideration of tutor and student roles in learner-focused strategies', in G. O'Neill, S. Moore \& B. McMullin (eds.), Emerging issues in the practice of university learning and teaching, pp. 87-98, AISHE, Dublin.

[10] N. M. Massa, J. Donnelly, and F. Hanes, "Student Reactions to Problem-Based Learning in Photonics Technician Education," in ETOP 2013 Proceedings, M. Costa and M. Zghal, eds., (2013) 